\title{
Holistic and Mechanical Combination in Psychological Assessment: Why Algorithms are Underutilized and What is Needed to Increase their Use
}

\author{
Marvin Neumann ${ }^{1}$, A. Susan M. Niessen ${ }^{1}$, Petra P. M. Hurks², \& Rob R. Meijer ${ }^{1}$ \\ ${ }^{1}$ Department of Psychometrics and Statistics, Faculty of Behavioral and Social Sciences, \\ University of Groningen \\ ${ }^{2}$ Department of Neuropsychology and Psychopharmacology, Faculty of Psychology and \\ Neuroscience, University of Maastricht
}

\section{Author note}

Marvin Neumann, https://orcid.org/0000-0003-0193-8159

A. Susan M. Niessen, https://orcid.org/0000-0001-8249-9295

Petra P. M. Hurks, https://orcid.org/0000-0002-4366-3707

Rob R. Meijer, https://orcid.org/0000-0001-5368-992X

Correspondence concerning this article should be addressed to Marvin Neumann, Department of Psychometrics and Statistics, Faculty of Behavioral and Social Sciences, University of Groningen, Grote Kruisstraat 2/1, 9712 TS Groningen, The Netherlands. Email: m.neumann@rug.nl.

Submitted for publication. This paper is currently under revision. 


\section{Data availability statement}

The data and R scripts that support the findings of our studies are openly available on OSF, https://osf.io/v3thf/.

\section{Conflict of interest}

None of the authors have a conflict of interest to disclose.

\section{Acknowledgements}

We thank the members of the recruitingrebels e.V. for filling in and distributing the survey from Study 1, and we thank Kienbaum Consultants International GmbH for supporting Study 2. We also thank the NIP for letting us recruit participants via a mailing list for Study 3. Lastly, we thank the participants in Study 3 for their fruitful insights on decision making in practice. 


\begin{abstract}
Although mechanical combination results in more valid human performance predictions and decisions than holistic combination, existing publications suggest that mechanical combination is rarely used in practice. Yet, these publications are either descriptions of anecdotal experiences or outdated surveys. Therefore, in several Western countries, we conducted two surveys (total $N=323$ ) and two focus groups to investigate (1) how decision makers in psychological assessment and HR practice combine information, (2) why they do (not) use mechanical combination, and (3) what may be needed to increase its use in practice. Many participants reported mostly using holistic combination, usually in teams. The most common reasons for not using mechanical combination were that algorithms are unavailable in practice and that stakeholders do not accept their use. Furthermore, decision makers do not quantify information, do not believe in research findings on evidence-based decision making, and think that combining holistic and mechanical combination results in the best decisions. The most important reason why mechanical combination is used was to increase predictive validity. To stimulate the use of mechanical combination in practice, decision makers indicated that they should receive more training on evidence-based decision making and that decision aids supporting the use of mechanical combination should be developed.
\end{abstract}

Keywords: algorithm aversion, personnel selection, holistic prediction, mechanical prediction, science-practice gap, decision aid, decision making 


\section{Practitioner points}

- Combining information with an algorithm (mechanical combination) results in more valid human performance predictions and decisions than combining information in the mind (holistic combination). Yet, decision makers rarely use mechanical combination in practice. To improve predictive validity, transparency, and the opportunity for learning, an algorithm should be used.

- Reasons reported by decision makers on why they rarely use mechanical combination were that they (1) do not and cannot quantify all available information, (2) do not believe in research findings on evidence-based decision making, and (3) think that a combination of mechanical and holistic combination results in the best predictions and decisions. Furthermore, decision makers indicated that they fear negative stakeholder evaluations when they would use algorithms.

- Decision makers showed many misunderstandings regarding holistic and mechanical combination, even after reading an elaborate explanation of the two methods.

- To improve decision making in practice, decision makers should be (1) trained in evidence-based decision making, (2) supported in designing evidence-based algorithms, and (3) encouraged to consult the academic literature on evidence-based decision making more regularly. 


\section{Holistic and Mechanical Combination in Psychological Assessment: Why Algorithms are Underutilized and What is Needed to Increase their Use}

Results from earlier but somewhat outdated surveys suggest that decision makers such as industrial and organizational (I-O) and clinical psychologists often combine information (e.g., test scores and interview impressions) holistically - i.e., based on their human judgment - to make performance predictions and selection decisions (Ryan \& Sackett, 1987; Vrieze \& Grove, 2009). These decision makers rarely use an algorithm to combine information; they are 'algorithm averse' (Dietvorst et al., 2015, p. 114). Holistic (clinical, impressionistic, or intuitive) combination generally results in moderately valid human performance predictions (Morris et al., 2015). Yet, the results from several large meta-analyses conducted across different domains involving human performance prediction showed that mechanical (statistical, actuarial, or algorithmic) combination results in more valid performance predictions than holistic combination (Dawes et al., 1989; Grove et al., 2000; Kuncel et al., 2013; Meehl, 1954). Predictions of job performance were even found to be 50\% more valid when made mechanically (Kuncel et al., 2013). Algorithm aversion is problematic ${ }^{1}$, because the use of holistic decision making results in suboptimal and intransparent predictions and decisions, which hinders the evaluation and improvement of the decision process (Meijer et al., 2020). Therefore, researchers called for (qualitative) investigations of why decision makers underutilize algorithms (Burton et al., 2020; Dietvorst et al., 2015; Neumann et al., 2021) and how decision making in selection can be improved (Meijer \& Niessen, 2022).

\section{Aims and Overview of the Present Studies}

The aims of this article were to update existing practitioner surveys, to get a clearer picture of how information is currently combined in practice, and, mainly, to investigate why decision makers underutilize algorithms. We expected underutilization based on existing

\footnotetext{
${ }^{1}$ Our aim was not to "condemn" decision makers who practice holistic combination, but to stimulate research on algorithm aversion, and to improve decision making in practice.
} 
findings on the use of holistic and mechanical combination (Ryan \& Sackett, 1987). Yet, professionals nowadays seem to increasingly interact with algorithmic solutions, both in everyday life and in high-stakes decision making about individuals. For example, algorithms may score game-based assessments and asynchronous interviews, scrape social media profiles, and give hiring recommendations (Gonzalez et al., 2019; Landers \& Behrend, 2022; Landers \& Sanchez, 2022). Therefore, it is also possible that the use of algorithms to make selection decisions has increased over time, which warrants an updated investigation of how selection decisions are made in practice.

Another aim was to identify factors that could promote algorithm use, assuming that algorithm use today is not optimal yet. To achieve these aims, we surveyed decision makers involved in personnel selection (reported below in Study 1 and 2, respectively) and organized two focus groups with I-O, educational, and clinical psychologists (Study 3). We invited decision makers with different backgrounds since the superiority of mechanical over holistic methods and algorithm aversion has been observed in virtually all social science fields (Grove et al., 2000). Our goal with these studies was to identify existing phenomena about how practitioners combine information (Eronen \& Bringmann, 2021) based on current attitudes and practical problems identified by practitioners regarding algorithm use, which is an essential, but often overlooked first step to theory development (Berkman \& Wilson, 2021; Ployhart \& Bartunek, 2019).

\section{Holistic and Mechanical Prediction}

When the aim of combining information is prediction - as it is in selection -, holistic and mechanical combination is also referred to as holistic and mechanical prediction. In holistic prediction, information is combined in the decision-maker's mind. In mechanical prediction, the same information is combined through an algorithm in the same way for all cases. While mechanical prediction is fully consistent and reproducible, holistic prediction is 
not; decision makers do not consistently use the same weights across applicants (Grove et al., 2000; Kuncel et al., 2013). Algorithms can vary from very simple additive formulas with only a few variables to more complex machine learning approaches (Fokkema et al., 2015). An example of a simple algorithm is to assign equal weights (i.e., unit weights, Bobko et al., 2007) to, for example, a test score and an interview rating, to add up the resulting scores, and to hire the highest scoring candidate(s). Yet, weights can also differ and can also be based on, for example, regression analyses, meta-analytic estimates, or even expert judgment (Kuncel, 2018). Alternatively, weights may be obtained by regressing decision-makers' holistic predictions on the predictors, which is also called "model of man" (Goldberg, 1970) or judgmental bootstrapping (Armstrong, 2001). So, algorithms neither have to be complex 'black boxes' nor be directly derived from data analysis. They can be simple, transparent, and designed by practitioners based on their knowledge. Such practitioner-designed algorithms can still outperform holistic prediction (Neumann, Niessen, et al., 2022; Yu \& Kuncel, 2020), as do simple algorithms with unit (Sackett et al., 2017) or even random weights (Dawes, 1979; Yu \& Kuncel, 2020), given that predictors do not differ substantially in validity.

Although often argued by practitioners, holistic and mechanical prediction cannot be used simultaneously, as one cannot both hire and reject the same candidate when the two methods disagree (for an example, see Grove \& Meehl, 1996). However, they can be used sequentially for the same prediction (Sawyer, 1966). In clinical synthesis, the decision maker makes a holistic prediction based on the collected information and an algorithm's prediction. In mechanical synthesis, the decision maker considers the collected information and makes a holistic prediction. This holistic prediction is subsequently multiplied by a fixed weight and algorithmically combined with all other information. Clinical synthesis classifies as holistic prediction since the final prediction is made holistically. Correspondingly, mechanical 
synthesis classifies as mechanical prediction, since the final prediction is derived algorithmically and hence consistently.

\section{The Prevalence of Holistic and Mechanical Prediction in Practice}

Publications that reported anecdotal experiences suggest that holistic combination is predominantly used in practice (Arkes, 2008; Grove \& Meehl, 1996; Highhouse, 2008). Yet, to the best of our knowledge, only a few surveys exist on the use of holistic and mechanical methods. Ryan and Sackett (1987) surveyed 163 members of the Society for Industrial and Organizational Psychology and found that only a small minority $(2.5 \%)$ used mechanical prediction in individual assessments. Other respondents reported combining information purely holistically (55.7\%) or using clinical synthesis (41.8\%). More recently, Ryan et al. (2015) surveyed 1197 human resource (HR) professionals from several countries on their test use and found that $43 \%$ indicated combining test scores and interview ratings in a standardized manner, although it is unclear how 'standardized' was defined or interpreted.

So, despite the robust research findings on evidence-based selection and decision making (Kuncel et al., 2013), our knowledge on how information is combined in practice is scarce and outdated or primarily anecdotal (Grove \& Meehl, 1996; Ryan \& Sackett, 1987). This is surprising, given that surveys on what assessment instruments are used to collect information are abundant (Furnham, 2008; Jackson et al., 2018; König et al., 2010; Mann \& Chowhan, 2011; Piotrowski \& Armstrong, 2006; Risavy et al., 2019; Zibarras \& Woods, 2010).

Research question 1: How do decision makers combine information in practice?

\section{Factors Related to Algorithm Aversion}

Various factors related to algorithm aversion in human performance prediction have been investigated (Neumann et al., 2021). Studies based on self-determination theory 
generally showed that algorithm use is higher when decision makers retain autonomy in mechanical combination, either by self-designing the algorithm (Nolan \& Highhouse, 2014) or by being able to holistically adjust predictions from a prescribed algorithm (clinical synthesis, Dietvorst et al., 2018). Furthermore, mechanical methods in which decision makers retain autonomy can result in more valid performance predictions than pure holistic combination (Dietvorst et al., 2018; Neumann, Niessen, et al., 2022).

In line with attribution theory, Nolan et al. (2016) found that decision makers were less likely to use an algorithm as a result of concerns about negative perceptions of stakeholders (e.g., colleagues or management) and the fear of losing professional status. Moreover, Diab et al. (2011) showed that laypeople considered algorithms to be less useful and more unprofessional, impersonal, and insufficient, compared to holistic prediction. Yet, another study showed that watching a short educational video on holistic and mechanical prediction increased algorithm use and hence prediction accuracy (Neumann, Hengeveld, et al., 2022).

In a sample of HR professionals, Lodato et al. (2011) found that an experiential decision-making style (i.e., a preference for making general judgments based on feelings) correlated positively and strongly with a preference for holistic prediction in selection procedures. In contrast, experience in HR management (in years), the possession of a certification as a senior HR professional and organization size were negatively and weakly correlated with a preference for holistic prediction. Furthermore, the frequency of reading work-related academic journals had a negligible but negative relationship with a preference for holistic prediction, although this small effect may have resulted from not defining the term “academic journals" in the survey (Lodato et al., 2011).

In summary, various factors that may be related to algorithm aversion were sometimes derived from theory and mostly tested in experimental study designs. Yet, the perspective of 
practitioners on algorithm aversion has rarely been entertained in earlier studies, although this is also important for identifying factors related to algorithm aversion (Ployhart \& Bartunek, 2019).

\section{Algorithm Appreciation}

Compared to algorithm aversion, we know little about when and why decision makers appreciate algorithms (Logg et al., 2019). Research on assessment instrument choices showed that validity/effectiveness, efficiency, fairness, and face validity were the most important factors why organizations employ tests in selection (Ryan et al., 2015). We expected that these factors also relate to (not) using algorithms. Since Lodato et al. (2011) found that experience, reading the academic literature, and possessing a certification were negatively yet weakly related to holistic prediction, we also aimed to investigate if these characteristics relate to algorithm use. We expected that obtaining a license and reading up on the superiority of algorithms in the academic literature should increase knowledge and hence algorithm use (Neumann, Hengeveld, et al., 2022). Moreover, we also explored the relation between experience and algorithm use since some evidence suggests that it is negatively related to algorithm use and prediction accuracy (Arkes et al., 1986; Logg et al., 2019), likely due to overconfidence of experienced decision makers (Arkes et al., 1986). So, given that practitioner-insights regarding algorithm aversion and appreciation are largely lacking, compared to insights from top-down research based on theory and experimental designs, we had the following research question:

Research question 2: Why do decision makers (not) use algorithms in practice? ${ }^{2}$

\section{Encouraging Algorithm Use in Practice}

\footnotetext{
${ }^{2}$ Compared to the pre-registration, we rephrased the research question to cover algorithm appreciation.
} 
Based on existing surveys, we expected that algorithms are underutilized. Therefore, we conducted focus groups to (1) explore reasons for algorithm aversion in more depth than is possible with surveys and (2) explore what decision makers need to apply algorithms in practice more often.

Research question 3: What do decision makers need to apply algorithms more often?

For the two standardized surveys and the focus group study reported below, the preregistrations, raw data, codebooks, R scripts, and study materials are available on https://osf.io/v3thf/?view_only=db9ed843dc3b43e6877c37341204dbb5

\section{Study 1}

\section{Participants}

We obtained a convenience sample via LinkedIn. This platform is typically used for survey research among practitioners involved in selection decisions (Jackson et al., 2018; Ryan et al., 2015). The first author distributed the online questionnaire in a German organization's private LinkedIn group whose mission is to bridge the science-practice gap, and whose members are interested in evidence-based assessment in personnel selection. Members of the private LinkedIn group are either members of the "recruiting rebels" organization who have paid an annual membership fee of $49 €$ or are potentially interested in becoming a member. Furthermore, we asked LinkedIn group members to share the survey link with other eligible decision makers who were not part of the LinkedIn group.

We only included participants who reported that they were involved in at least five hiring decisions in the last two years, through making (part of) the hiring decision or providing consultation to others who made the decision. One participant who indicated to be 
younger than 18 was excluded. In total, we obtained usable data from $N=93^{3}$ participants ( $54 \%$ female) who ranged in age from 25 to $60(M=38.2, S D=9.4)$. The sample was primarily German (95\%) and 54\% of the participants were part of the organization's private LinkedIn group. The other participants had other European nationalities. Most participants held a Bachelor's or Master's degree (88\%), mostly in psychology, HR management, or business (69\%). Furthermore, participants' mean organizational tenure was $6.5(S D=7.9)$ and role tenure was $4.1(S D=5.1)$. The mean number of years participants were involved in making hiring decisions was $9.8(S D=7.6)$. Additional demographic information can be found in Supplement S1, Table S1. The median survey completion time was 13 minutes.

\section{Procedure}

Figure 1 depicts the survey flow. Participants reported their experience and indicated whether they use more than one source (i.e., assessment instrument) to obtain information about applicants. Those who indicated using only one source $(n=1)$ were asked why, and what source they use. Participants who indicated using multiple sources $(n=92)$ reported how frequently $(1=$ never, 5 =always $)$ they use several methods to combine information, and which method they use most often (see Table 1; results from Study 1 and Study 2 are also included in this Table, but are further discussed in the results sections below).

\footnotetext{
${ }^{3}$ We had pre-registered to collect data from minimally $N=171$ participants who report not always using mechanical prediction, to achieve a desired margin of error for observed proportions. Furthermore, the results from an a priori power analysis showed that, for a regression model given five predictors, $\alpha=.05,1-\beta=.80$, and $R^{2}=.09, N=136$ participants would be needed. We reposted the survey link several times and explicitly asked key organizational members to share the link with their network. After a prolonged time of no additional survey completions, we had to stop the data collection, which lasted from April to October 2021. A post-hoc power analysis showed that power was .67 (given the observed effect size $R^{2}{ }_{\text {adj. }}=.10, \alpha=.05$, and $N=92$; one participant reported only using one source to obtain information about applicants).
} 


\section{Figure 1}

The Survey Flow in Study 1

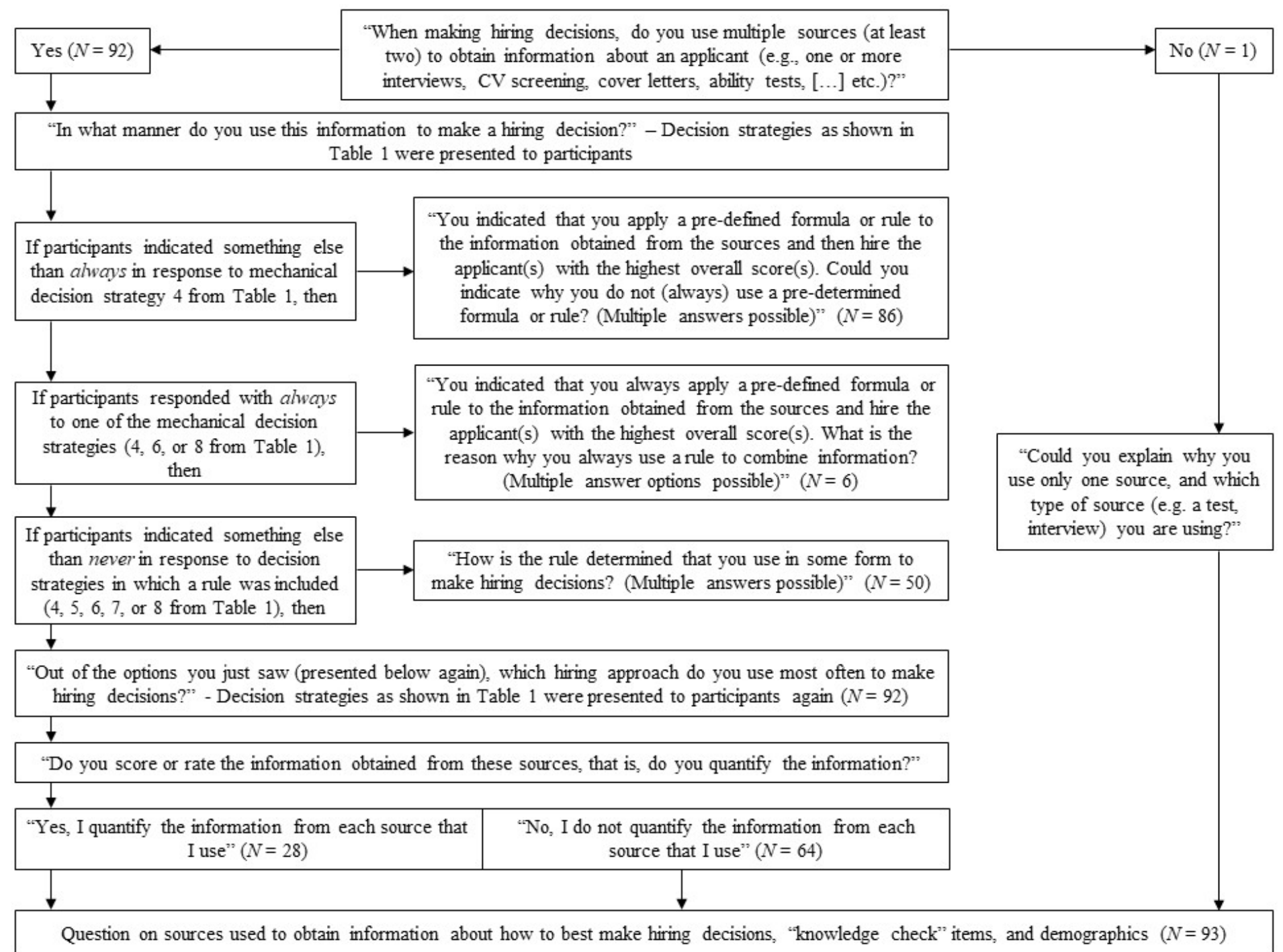




\section{Table 1}

Combination Methods Presented to Participants and Results from Study 1 and Study 2

\begin{tabular}{|c|c|c|c|c|c|c|}
\hline \multirow[t]{2}{*}{ Combination Method } & \multicolumn{3}{|c|}{ Study $1(N=92)$} & \multicolumn{3}{|c|}{ Study $2(N=228)$} \\
\hline & $\begin{array}{l}\text { Frequency of } \\
\text { most often used } \\
\text { combination } \\
\text { method }\end{array}$ & $M$ & $S D$ & $\begin{array}{l}\text { Frequency of } \\
\text { most often used } \\
\text { combination } \\
\text { method }\end{array}$ & $M$ & $S D$ \\
\hline $\begin{array}{l}\text { 1. I do not consider upfront how important the information obtained from } \\
\text { these sources is. I reach a decision by integrating the information using } \\
\text { my own judgment. }(\mathrm{H})^{a}\end{array}$ & $4(4 \%)$ & 2.14 & 1.12 & $7(3 \%)$ & 3.07 & 1.22 \\
\hline $\begin{array}{l}\text { 2. First, I consider how important the information obtained from these } \\
\text { sources is, and then I reach a decision by integrating the information } \\
\text { using my own judgment. }(\mathrm{H})\end{array}$ & $21(23 \%)$ & 3.12 & 1.18 & $67(29 \%)$ & 3.57 & 0.87 \\
\hline $\begin{array}{l}\text { 4. I apply a pre-defined formula or rule to the information obtained from } \\
\text { these sources and I hire the applicant(s) with the highest overall score(s). } \\
\text { Exemplary rule: Overall score }=\text { Test score*0.5 + Interview rating*0.3+ } \\
\text { CV rating*0.2. (M) }{ }^{b}\end{array}$ & $2(2 \%)$ & 1.53 & 1.00 & $16(7 \%)$ & 3.38 & 1.09 \\
\hline
\end{tabular}


5. First, I apply a pre-defined formula or rule to the information obtained $2(2 \%)$

$\begin{array}{ll}1.16 & 0.50\end{array}$

$19(8 \%)$

$3.37 \quad 1.03$

from these sources. Exemplary rule: Overall score $=$ Test score*0.5+

Interview rating*0.3 $+\mathrm{CV}$ rating*0.2. Then I may adjust this overall score using my own judgment in case I think this is needed. $(\mathrm{H})$

6. I apply a pre-defined formula or rule to the information obtained from

$1.28 \quad 0.75$

0.75

$15(7 \%)$

$3.25 \quad 1.07$

these sources, but I also explicitly add my own rating with a fixed weight in this rule. Then I hire the applicant(s) with the highest overall score(s). Exemplary rule: Overall score $=$ Test score*0.4 + Interview rating*0.2 + CV rating*0.1 + own rating*0.3. (M)

7. First, I determine cutoffs, and applicants who fall above these cutoffs progress to the next stage in the hiring process. Exemplary rule: Progress to the next stage $=\mathrm{A}$ test percentile score equal to or higher than $50 \%$ and an interview rating of 3 or higher (on a five-point scale). To make the final hiring decision, I use my own judgment. $(\mathrm{H})$

8. First, I determine cutoffs, and applicants who fall above these cutoffs progress to the next stage in the hiring process. Exemplary rule: Progress

$\begin{array}{llllll}9(10 \%) & 1.71 & 1.22 & 9(4 \%) & 3.48 & 0.95\end{array}$
to the next stage $=\mathrm{A}$ test percentile score equal to or higher than $50 \%$ and an interview rating of 3 or higher (on a five-point scale). To make the final hiring decision, I use a pre-determined formula or rule. (M)

Note. Participants reported how frequently they use the presented combination methods. $1=$ never, $2=$ rarely, $3=$ sometimes, $4=$ usually, $5=$ always. ${ }^{\mathrm{a}} \mathrm{H}=$ Holistic. ${ }^{\mathrm{b}} \mathrm{M}=$ Mechanical. 
Participants who reported that they do not always use an algorithm (decision strategy 4 in Table $1, n=86$ ) selected pre-listed reasons why they do not always use an algorithm (see Table 2). This list was derived from theories that have been tested in the context of algorithm aversion in selection (Neumann et al., 2021), reasons that have been mentioned in position papers (Arkes, 2008; Grove \& Meehl, 1996; Highhouse, 2008), and other reasons that we encountered during earlier conversations with decision makers. Participants could also report additional, other reasons via a text field. Participants who reported always using algorithms (decision strategy 4,6 , or 8 in Table $1, n=6$ ) were asked to select pre-listed reasons why they do so. This list was based on factors that explain the use of different data collection methods (König et al., 2010; Ryan et al., 2015). However, the relationship between these factors and data combination methods has not been studied before. 


\section{Table 2}

Reasons Not to Use an Algorithm - Results from Study 1 and Study 2

\begin{tabular}{|c|c|c|}
\hline Reasons Not to Use an Algorithm & Study $1(N=86)$ & Study $2(N=163)$ \\
\hline & Proportion and $95 \% \mathrm{CI}$ & Proportion and 95\% CI \\
\hline I use qualitative information that I cannot or do not want to quantify. & $.35[.25, .45]$ & $.18[.12, .24]$ \\
\hline There are no rules available. & $.30[.21, .40]$ & $.16[.10, .22]$ \\
\hline The use of a rule is not accepted by other people around me (e.g., colleagues, supervisors). & $.24[.15, .33]$ & $.28[.21, .35]$ \\
\hline $\begin{array}{l}\text { I think that using a rule together with my own judgment results in the best (i.e., most valid) } \\
\text { decisions. }\end{array}$ & $.21[.12, .30]$ & $.23[.16, .29]$ \\
\hline Other & $.21[.12, .30]$ & 0 \\
\hline $\begin{array}{l}\text { I do not believe that using a rule results in better (i.e., more valid) decisions than combining } \\
\text { information through my own judgment. }\end{array}$ & $.20[.11, .28]$ & $.25[.18, .32]$ \\
\hline $\begin{array}{l}\text { I think that using a rule will result in a less diverse workforce than combining information } \\
\text { through my own judgment. }\end{array}$ & $.20[.11, .28]$ & $.13[.08, .19]$ \\
\hline I think it is my duty as a professional to use my own judgment rather than a rule. & $.16[.08, .24]$ & $.23[.17, .30]$ \\
\hline $\begin{array}{l}\text { I (have to) select personnel based on criteria that are difficult to make explicit (e.g., } \\
\text { personal liking, acquaintance). }\end{array}$ & $.15[.08, .23]$ & $.11[.06, .16]$ \\
\hline $\begin{array}{l}\text { I am not aware that using a rule results in better (i.e., more valid) decisions than combining } \\
\text { information through my own judgment. }\end{array}$ & $.14[.07, .21]$ & $.20[.14, .26]$ \\
\hline I do not know how to construct such a rule. & $.14[.07, .21]$ & $.08[.04, .12]$ \\
\hline I do not have the time to read the academic literature on the use of rules. & $.12[.05, .18]$ & $.04[.01, .07]$ \\
\hline
\end{tabular}


I feel my autonomy in the hiring process is restricted when using a rule.
$.09[.03, .15]$

$.07[.02, .12]$

$.06[.01, .11]$

$.05[.00, .09]$

$.03[.00, .07]$

0
$.23[.16, .29]$

$.05[.02, .08]$

I feel my personal contact with other decision makers is reduced when using a rule.

I feel I cannot demonstrate my competence when using a rule.

I feel my professional status is lowered when using a rule.

I am concerned that using a rule will be against the law.

Note. Multiple answers possible. 
Those who indicated using a decision strategy that in some form includes an algorithm (decision strategy 4,6 , or 8 in Table $1, n=50$ ) to some extent (i.e., more often than "never") selected pre-listed approaches of how they construct their algorithm (see Table 3). This list was composed of approaches to mechanical data combination as presented in Kuncel's (2018) taxonomy. Specifically, Kuncel (2018) distinguished between unit weights, criterion-derived weights (weights based on empirical results from regression analyses, previous meta-analyses, or zero-order correlations), and bootstrapped weights. We did not include a combination method based on bootstrapped weights because we have never observed this combination method in practice and because we expected that participants would not understand this answer option without adding an extensive explanation that would have substantially lengthened the survey. Although not explicitly included in Kuncel's (2018) taxonomy, weights can also be directly chosen by decision makers. This choice can be based on gut feeling or knowledge of the scientific literature. We call this approach 'judgmental weighting'.

Furthermore, participants who indicated using multiple sources reported whether they quantify information obtained from each source, because mechanical prediction requires quantified information. Moreover, all participants indicated how frequently they consult several sources (e.g., other professionals, academic or professional literature) to obtain information about how to best make hiring decisions (see Table 4), and whether they possess an assessment license (German DIN 33430).

Lastly, after reading an explanation on the distinction between holistic and mechanical prediction, participants indicated for each of three fictitious hiring scenarios whether information was combined holistically, mechanically, or whether they could not tell without further information. These "knowledge check" items were administered to investigate whether participants understood the distinction between holistic and mechanical prediction. The items 
were administered at the end of the survey to avoid potentially socially desirable answers on questions regarding how decision makers typically combine information. 


\section{Table 3}

Ways to Construct an Algorithm - Results from Study 1 and Study 2

\begin{tabular}{|c|c|c|c|}
\hline Ways to Construct an Algorithm & & Study $1(N=50)$ & Study $2(N=221)$ \\
\hline & $\begin{array}{c}\text { Label of the Data } \\
\text { Combination Method in } \\
\text { Kuncel's (2018) } \\
\text { Taxonomy }\end{array}$ & Proportion and $95 \% \mathrm{CI}$ & Proportion and $95 \% \mathrm{CI}$ \\
\hline $\begin{array}{l}\text { I determine the rule based on a discussion with } \\
\text { experts/professionals. }\end{array}$ & Judgmental weighting $^{\text {a }}$ & $.42[.28, .56]$ & $.32[.26, .38]$ \\
\hline $\begin{array}{l}\text { I determine the rule based on scientific research (meta-analyses } \\
\text { or primary scientific studies). }\end{array}$ & $\begin{array}{l}\text { Criterion-derived } \\
\text { weights }\end{array}$ & $.34[.21, .47]$ & $.43[.36, .49]$ \\
\hline $\begin{array}{l}\text { I determine the rule based on my own knowledge and } \\
\text { experience, without consulting the scientific literature or others. }\end{array}$ & Judgmental weighting ${ }^{\text {a }}$ & $.32[.19, .45]$ & $.33[.26, .39]$ \\
\hline $\begin{array}{l}\text { I use a rule as prescribed or suggested by others (e.g., by the } \\
\text { organization you are working for or by professional standards). }\end{array}$ & $\begin{array}{l}\text { Criterion-derived } \\
\text { weights / Unit-weights / } \\
\text { Judgmental weighting a }\end{array}$ & $.28[.16, .40]$ & $.24[.19, .30]$ \\
\hline $\begin{array}{l}\text { I determine the rule based on statistical analyses of data that } \\
\text { come from my organization, or other relevant data. }\end{array}$ & $\begin{array}{l}\text { Criterion-derived } \\
\text { weights }\end{array}$ & $.24[.12, .36]$ & $.54[.48, .61]$ \\
\hline I weight all relevant information evenly (the same weights). & Unit-weights & $.10[.02, .18]$ & $.44[.37, .50]$ \\
\hline
\end{tabular}

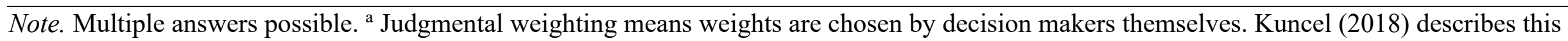
weighting option but did not explicitly include it in his taxonomy. 


\section{Table 4}

Information Sources in Study 1 and Study 2

\begin{tabular}{|c|c|c|c|c|}
\hline \multirow[t]{2}{*}{ Information Sources } & \multicolumn{2}{|c|}{ Study $1(N=93)$} & \multicolumn{2}{|c|}{ Study $2(N=230)$} \\
\hline & $M$ & $S D$ & $M$ & $S D$ \\
\hline Other (HR) professionals & 3.10 & 1.11 & 3.47 & 0.99 \\
\hline (HR) blogs, videos, websites & 2.86 & 1.27 & 3.56 & 1.16 \\
\hline Professional HR literature (e.g., Harvard & 2.76 & 1.09 & 3.35 & 1.13 \\
\hline \multicolumn{5}{|l|}{ Business Review, MIT Sloan Management } \\
\hline \multicolumn{5}{|l|}{ Review, HR Magazine) } \\
\hline Scientific literature (Academic journals, e.g., & 2.34 & 1.15 & 3.23 & 1.25 \\
\hline \multicolumn{5}{|l|}{ Journal of Applied Psychology, International } \\
\hline \multicolumn{5}{|l|}{ Journal of Selection and Assessment, Human } \\
\hline \multicolumn{5}{|l|}{ Resource Management) } \\
\hline Popular magazines (e.g., Forbes, Fortune, Fast & 2.09 & 1.11 & 3.23 & 1.21 \\
\hline \multicolumn{5}{|l|}{ Company, Inc., Workforce) } \\
\hline External consultants & 1.73 & 0.96 & 3.03 & 1.11 \\
\hline Scientists (university staff) & 1.71 & 0.98 & 3.01 & 1.34 \\
\hline
\end{tabular}

Note. $1=$ never or rarely, $2=$ a few times per year, $3=$ about once a month, $4=$ several times per month, 5 = almost daily. We gave slightly different examples of the professional HR literature and the popular magazines than presented in this Table in Study 1, given that our sample in Study 1 was primarily German. The exact examples can be found in the study materials on OSF, https://osf.io/v3thf/?view_only=db9ed843dc3b43e6877c37341204dbb5 


\section{Results}

All but one participant reported using multiple sources to obtain information about applicants. Table 1 shows the mean frequency ratings and the number of participants who indicated using a given method most often, for each combination method. We collapsed these methods into the two holistic and mechanical meta-categories by averaging participants' frequency responses to combination method $1,2,3,5$, and 7 , and 4,6 , and 8 , respectively (see Table 1 for the numbering). Holistic methods are by far most often used (87\%). Similarly, the mean frequency rating for holistic methods was much higher $(M=2.38, S D=0.58)$ than for mechanical methods $(M=1.51, S D=0.76, d=1.29,95 \%$ CI $[0.89,1.70])$. Furthermore, from the participants who reported using some form of holistic prediction most often $(n=80), 55 \%$ reported making predictions in a team discussion, while $31 \%$ reported making holistic predictions individually. Moreover, 14\% reported using clinical synthesis (combination method 5 and 7), mostly in the form of multi-stage selection. That is, first selecting applicants who pass pre-determined cutoffs and then selecting among the final candidates based on one's own judgment. Among participants who used some form of mechanical prediction most often $(n=12), 75 \%$ reported that they first select applicants who pass pre-determined cutoffs and then use a pre-determined algorithm to make final hiring decisions.

Furthermore, most participants indicated that they do not quantify all obtained information (70\%). We also asked participants who reported not always using some form of mechanical prediction $(n=86)$ why (see Table 2$)$. The most common reason was that participants cannot or do not want to quantify all information (35\%). Other frequently reported reasons were that algorithms are unavailable (30\%) and not accepted by stakeholders (e.g., supervisors and colleagues, 24\%). Furthermore, participants believed that using an algorithm together with one's own judgment would result in the most valid decisions $(21 \%)$. Moreover, 14\% indicated not knowing that mechanical prediction is more valid than holistic 
prediction. Less frequently mentioned reasons were that using algorithms would reduce one's perceived competence (5\%) and professional status (3\%). Moreover, no participant was concerned that using an algorithm would be against the law. Mentioned reasons not pre-listed in the survey were that other decision makers can veto decisions in a group discussion $(n=4)$, and that algorithms, or selection in general, would be unnecessary due to a lack of applicants $(n=5)$. To investigate when decision makers appreciate algorithms, we asked those who always use an algorithm why. Yet, only six participants reported always using an algorithm. Therefore, no specific results on that subsample are reported.

Participants who indicated using some form of mechanical prediction at all $(n=50)$ were also asked how they construct their algorithm (see Table 3). The most common way was by means of discussion with experts/professionals (42\%). Other common strategies were to design an algorithm based on scientific research (meta-analyses or primary scientific studies, $34 \%$ ) or based on one's own knowledge and expertise, without consulting the scientific literature or others $(32 \%)$. Some participants also indicated that they use an algorithm as prescribed by others (e.g., by their organization or professional standards, $28 \%$ ) or that they base their algorithm on statistical analyses of data from their organization, or other relevant data $(24 \%)$. Unit weighting was the least common way $(10 \%)$.

\section{Information Sources}

Participants reported that they most frequently obtain information on how to best make selection decisions by consulting other HR professionals (see Table 4). Similarly, blogs, videos, websites, and popular magazines such as Harvard Business Review were frequently consulted. Compared to these sources, participants consulted the academic literature (e.g., Journal of Applied Psychology) less frequently. Moreover, scientists and external consultants were rarely consulted.

\section{Knowledge Check}


After reading the explanation of holistic and mechanical prediction, $32 \%$ out of all participants who obtained a college degree $(n=87)$ indicated that holistic and mechanical prediction was discussed in their studies. Afterwards, participants indicated for three fictitious hiring scenarios whether the information was combined holistically, mechanically, or whether they cannot tell without further information. Out of all participants, $43 \%$ answered all three "knowledge check" items correctly, while 77\% answered at least two items correctly. At least one item was answered correctly by $95 \%$ of all participants.

\section{Individual Characteristics}

Means, standard deviations, and Spearman's rank correlations among study variables are shown in Table 5. We computed Spearman's rank correlations instead of Pearson's correlation coefficient because the variables "mechanical prediction" and "experience (in years)" were positively skewed. As expected based on Lodato's et al. (2011) results, we also found that reading the academic literature and possessing an assessment license were significantly positively yet weakly to moderately related to using mechanical prediction methods ( $r=.26$ and .25 , respectively). In contrast, experience in making hiring decisions (measured in years and the amount of decisions made) and organization size showed negligible relationships with using mechanical methods. We also fitted a regression model with mechanical prediction as the dependent variable and academic literature, assessment license, organization size, experience (in years), and experience (amount) as independent variables (see Table 6). Together, the predictors explained $15 \%$ of the variance in the use of mechanical prediction methods $\left(F(5,86)=3.05, p=.014, R^{2}\right.$ adj. $\left.=.10\right)$. To assess variable importance, we also computed relative importance weights using the relaimpo $\mathrm{R}$ package (Grömping, 2006). As Figure 2 shows, reading the academic literature and possessing an assessment license were the most important predictors. Based on the suggestion of an anonymous reviewer, we also fitted the same regression model with holistic prediction as the 
dependent variable (see Table 6). Together, the predictors explained $15 \%$ of the variance in the use of mechanical prediction methods $\left(F(5,86)=2.71, p=.026, R^{2}\right.$ adj. $\left.=.09\right)$. In line with expectations, reading the academic literature was negatively related to the use of holistic methods. All other predictors were not statistically significant. 


\section{Table 5}

Means, Standard Deviations, and Spearman's Rank Correlations among Study Variables in Study 1 and Study 2

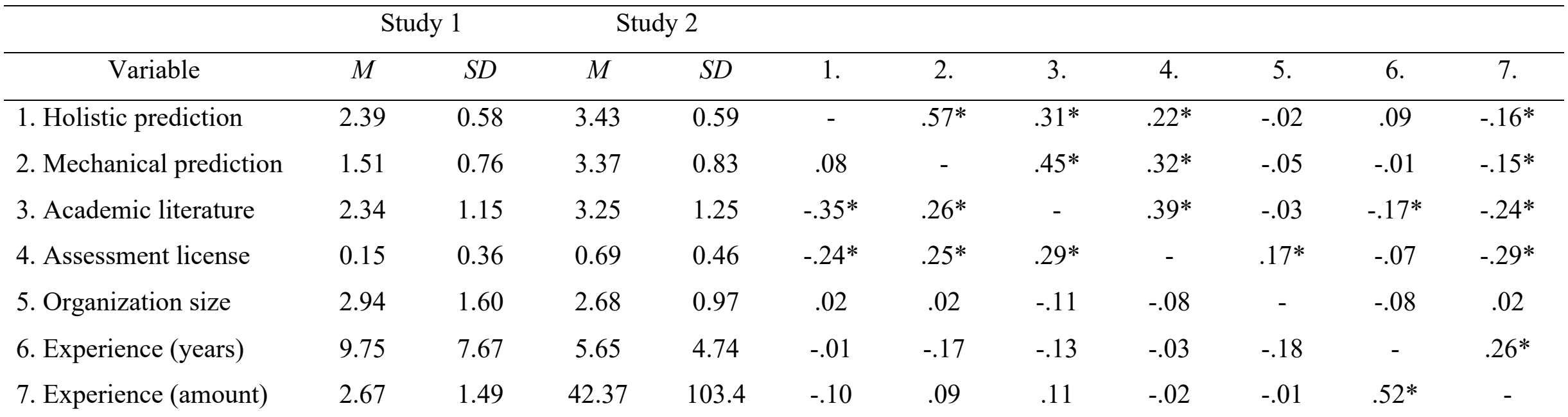

Note. ${ }^{*} p<.05$, two tailed. Correlations among study variables in Study 1 are shown below the diagonal. Correlations among study variables in Study 2 are shown above the diagonal. Assessment license (DIN 33430 in Study 1 and SHRM in Study 2) was coded as $0=$ No, $1=$ Yes.

Organization size was measured on a five-point scale $(1=$ less than 100, $2=100-499,3=500-1999,4=2000-4999,5=$ more than 5000). Experience (amount) was measured on a five-point scale $(1=1-49,2=50-99,3=100-199,4=200-499,5=500$ or more) in Study 1 and on a continuous scale in Study 2. The sample size in Study 1 was $N=92-93$. The sample size in Study 2 was $N=228-230$. 


\section{Table 6}

Regression Results from Study 1 and Study 2

\begin{tabular}{|c|c|c|c|c|c|c|c|c|c|}
\hline \multirow{2}{*}{$\begin{array}{c}\text { Study } \\
\text { Study } 1\end{array}$} & \multirow[t]{2}{*}{ Predictor } & \multicolumn{4}{|c|}{ DV: Mechanical Prediction } & \multicolumn{4}{|c|}{ DV: Holistic Prediction } \\
\hline & & $\begin{array}{c}\text { Estimate } \\
(b)\end{array}$ & $\mathrm{SE}(b)$ & $t$ & $p$ & $\begin{array}{c}\text { Estimate } \\
(b)\end{array}$ & $\mathrm{SE}(b)$ & $t$ & $p$ \\
\hline & Intercept & 0.98 & 0.28 & 3.48 & $<.01$ & 2.90 & 0.22 & 13.31 & $<.001$ \\
\hline & Academic literature & 0.12 & 0.07 & 1.67 & .10 & -0.15 & 0.06 & -2.73 & .008 \\
\hline & Assessment license & 0.45 & 0.22 & 2.03 & .045 & -0.24 & 0.17 & -1.39 & .169 \\
\hline & Organization size & 0.03 & 0.05 & 0.60 & .547 & -0.03 & 0.04 & -0.71 & .48 \\
\hline & Experience (years) & -0.02 & 0.01 & -1.42 & .16 & -0.002 & 0.01 & -0.21 & .833 \\
\hline & Experience (amount) & 0.10 & 0.06 & 1.59 & .115 & -0.01 & 0.05 & -0.27 & .79 \\
\hline \multicolumn{10}{|l|}{ Study 2} \\
\hline & Intercept & 2.31 & 0.21 & 10.95 & $<.001$ & 2.83 & 0.17 & 16.95 & $<.001$ \\
\hline & Academic literature & 0.26 & 0.04 & 6.22 & $<.001$ & 0.14 & 0.03 & 4.33 & $<.001$ \\
\hline & Assessment license & 0.38 & 0.11 & 3.41 & $<.001$ & 0.15 & 0.09 & 1.66 & .099 \\
\hline & Organization size & $<0.01$ & 0.05 & 0.09 & .93 & -0.01 & 0.04 & -0.33 & .741 \\
\hline & Experience (years) & -0.01 & 0.01 & -0.91 & .36 & 0.01 & 0.01 & 1.78 & .077 \\
\hline & Experience (amount) & $<-0.01$ & $<0.01$ & -0.68 & .50 & $<-0.001$ & $<0.001$ & -1.061 & .29 \\
\hline
\end{tabular}

Note. The sample size was $N=92$ in Study 1 and $N=228$ in Study 2 . 


\section{Figure 2}

Relative Weights for Predicting the Use of Mechanical Prediction Methods in Study 1

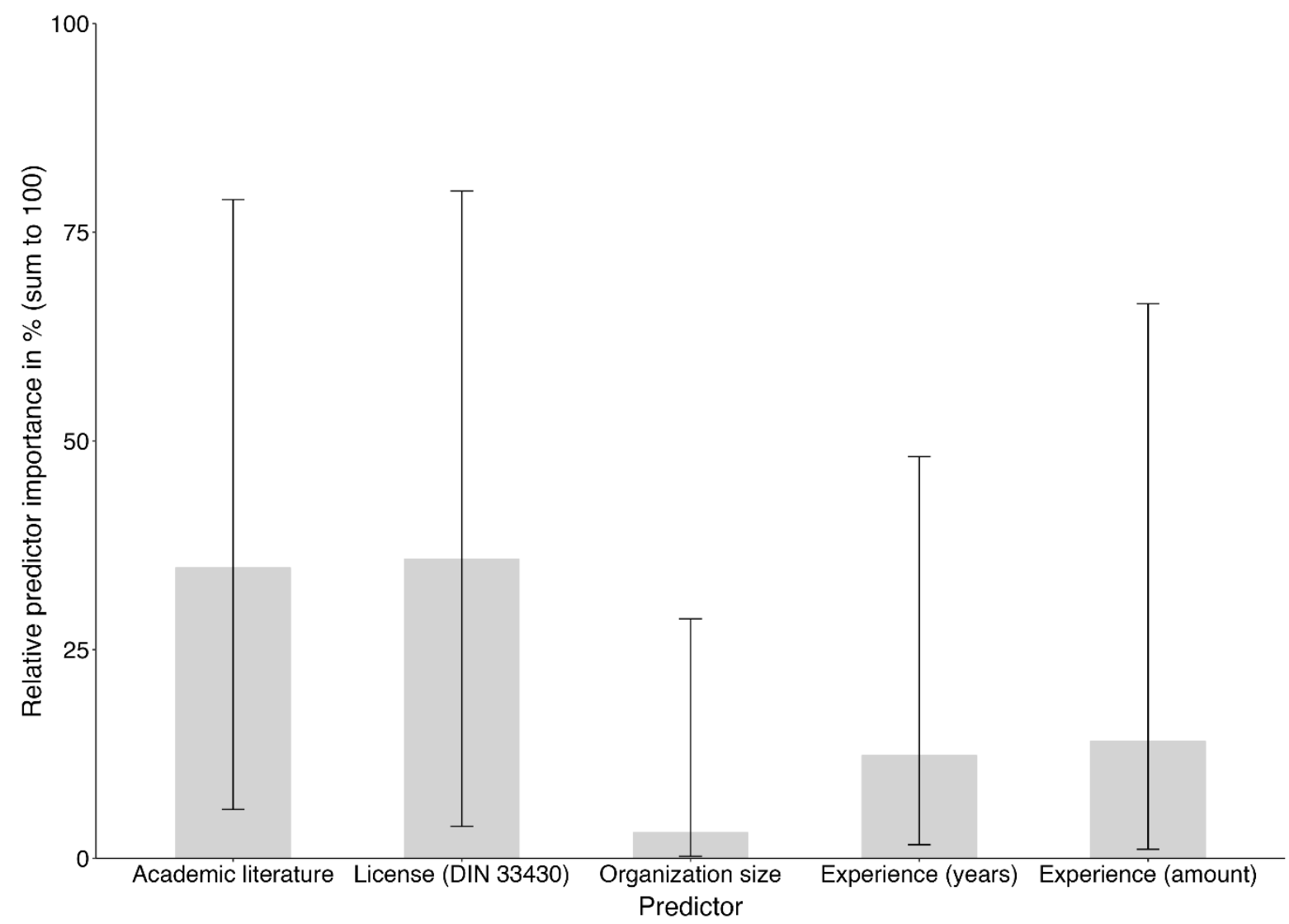

Note. Error bars represent $95 \%$ bootstrap confidence intervals.

\section{Study 2}

The aim of the second study was to replicate the results from Study 1 using a larger sample that was collected via Amazon Mechanical Turk. We displayed the different combination methods in random order, to prevent order effects. Furthermore, in Study 1, only six participants reported always using algorithms and hence selected reasons why. This subsample was too small for meaningful interpretation. Therefore, in Study 2, all participants who indicated using algorithms at all (i.e., more than "never") selected reasons why. Since we expected participants to be mostly U.S. citizens, we slightly revised the sources that participants may consult to obtain information about how to best make hiring decisions. Furthermore, we asked participants if they possess a SHRM license instead of the German 
DIN 33430 license. Except for these changes and additional exclusion criteria presented below, the survey was the same as in Study 1.

\section{Participants}

The study was introduced as a general study on decision making, to avoid that participants guessed the exclusion criteria. Participants indicated up to three (from a list of twelve, presented in random order) work activities that they most frequently engage in at work (see Supplement S2). Only participants who selected "staffing organizational units", “making decisions and solving problems", or "judging the qualities of things, services, and people" were included. As in Study 1, we excluded participants who reported that they were involved in less than five hiring decisions in the last two years, meaning making (part of) the hiring decision or providing consultation to others who made the decision. Furthermore, participants who failed at least one of two attention checks (see Supplement S3) were excluded. Although not pre-registered, we also excluded participants who were younger than 18, or who gave impossible responses to some questions (e.g., a higher organizational role tenure than organizational tenure), which indicated that they may not have completed the study seriously. We retained usable data from $N=230$ participants (55\% male) who ranged in age from 21 to $67(M=36.4, S D=10.3)$. The sample consisted primarily of U.S. citizens $(89 \%)$. Other participants had other non-European $(10 \%)$ or European nationalities $(<0.01 \%)$. As in Study 1, the majority of participants held a Bachelor's or Master's degree (93\%), mostly in psychology, HR management, or business. Participants' mean organizational tenure was 6.9 years $(S D=4.3)$ and role tenure was $4.5(S D=2.8)$. The mean number of years participants were involved in making hiring decisions was 5.6 $(S D=4.7)$. Additional demographic information is displayed in Supplement S4, Table S1. The median survey completion time was 12 minutes.

\section{Results}


Most of the results found in Study 1 were similar in Study 2.

\section{Similarities}

All but two participants reported using multiple sources to obtain information about applicants. Also, holistic methods were used most often ( $82 \%$, see Table 1). Furthermore, the results from participants who reported using some form of holistic prediction most often $(n=$ 188) showed that making holistic team predictions was prevalent (41\%), although almost as prevalent as individual holistic predictions (39\%). Moreover, 20\% reported using clinical synthesis.

Although the reasons for not using algorithms were also similar (see Table 2), relatively more participants indicated that they feel their status $(23 \%)$, autonomy $(23 \%)$, and personal contact with other decision makers $(21 \%)$ is reduced when using an algorithm. Relatively less participants than in Study 1 indicated that they do not use algorithms because algorithms are unavailable $(16 \%)$ or because they cannot or do not want to quantify information (18\%).

Participants indicated that they frequently consult blogs, videos, websites, other (HR) professionals, and the professional (HR) literature to obtain information on how to best make selection decisions (see Table 4). They consulted the academic literature somewhat less frequently and rarely consulted scientists or external consultants. Furthermore, we found similar relations between individual characteristics and the use of mechanical methods as in Study 1 (see Table 5). In line with expectations, reading the academic literature and possessing an assessment license were positively and moderately correlated with the use of mechanical prediction methods ( $r=.45$ and .32 , respectively). Yet, in contrast to Study 1 , we found a strong positive correlation between using holistic and mechanical methods. Unexpectedly, reading the academic literature and possessing an assessment license were also positively and moderately correlated with the use of holistic prediction methods $(r=.31$ and 
.22 , respectively). As in Study 1, we fitted two regression models with holistic and mechanical prediction as the dependent variables, and academic literature, assessment license, organization size, experience (in years), and experience (amount) as independent variables (see Table 6). Together, the predictors explained $30 \%$ of the variance in mechanical prediction $\left(F(5,222)=18.58, p<.001, R^{2}\right.$ adj. $\left.=.28\right)$, and reading the academic literature and possessing an assessment license were the most important predictors (see Figure 3).

Furthermore, the predictors explained $14 \%$ of the variance in holistic prediction $(F(5,222)=$ $7.07, p<.001, R^{2}$ adj. $=.12$ ). Unexpectedly, reading the academic literature was positively related to the use of holistic methods.

\section{Figure 3}

Relative Weights for Predicting the Use of Mechanical Prediction Methods in Study 2

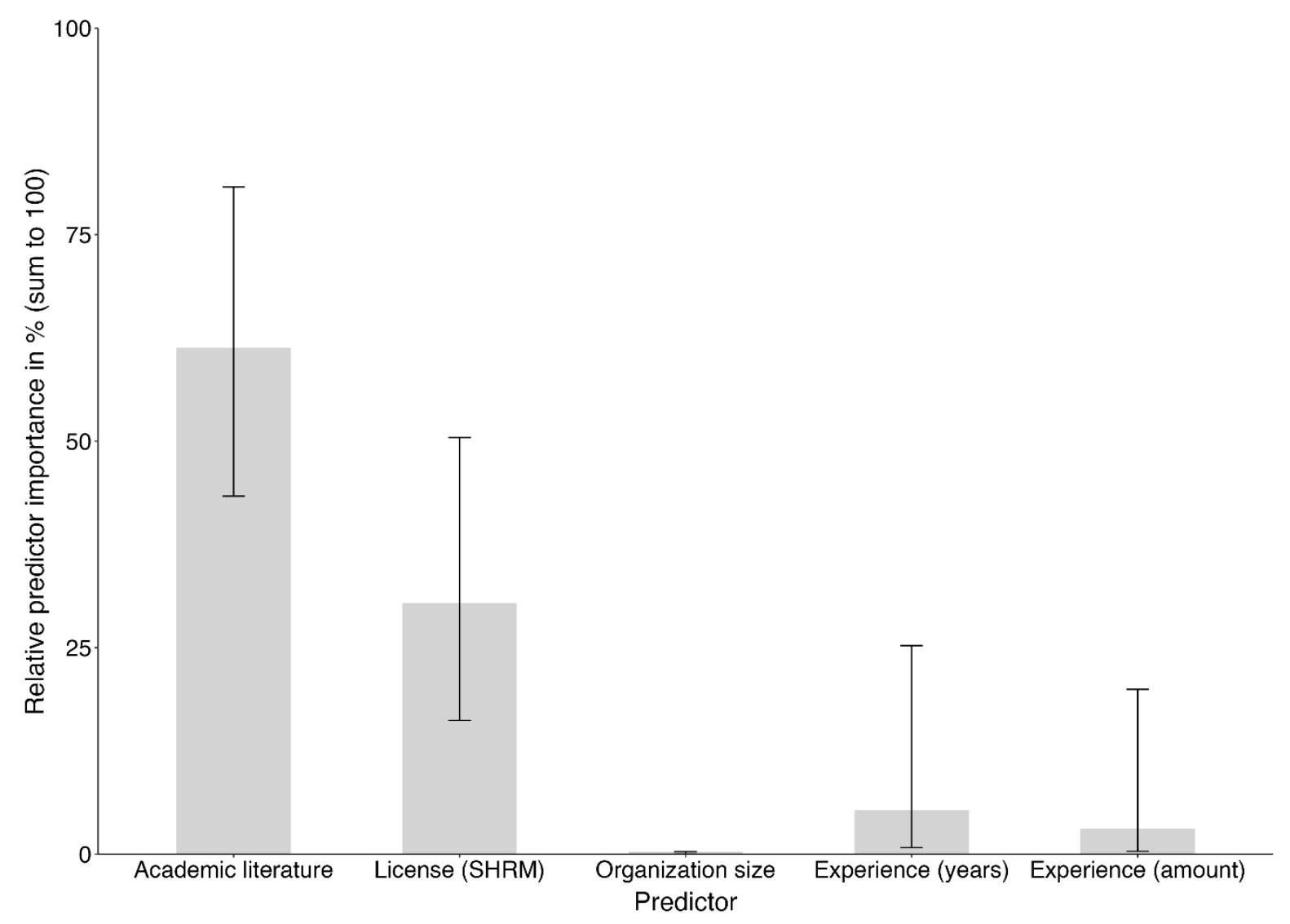

Note. Error bars represent $95 \%$ bootstrap confidence intervals. 


\section{Differences}

In contrast to Study 1, only a small minority indicated that they do not quantify all information (11\% versus $70 \%$ in Study 1). Furthermore, the mean frequency rating for holistic methods $(M=3.43, S D=0.59)$ was similar to the mean frequency rating for mechanical methods $(M=3.37, S D=0.83, d=0.09,95 \%$ CI $[-0.03,0.20])$, whereas in Study 1 the mean frequency for holistic methods was much higher than for mechanical methods. Moreover, in Study 2, many more participants who obtained a college degree $(n=216)$ indicated that holistic and mechanical prediction was discussed in their studies (90\% versus $32 \%$ in Study 1). Yet, only 7\% (versus $43 \%$ in Study 1 ) out of all participants answered all three "knowledge check" items correctly, while $42 \%$ (versus 77\%) answered at least two items correctly. Out of all participants, 70\% (versus 95\%) answered at least one item correctly ${ }^{4}$. Participants who indicated that they at least rarely use some form of mechanical prediction $(n=221)$ were also asked how they construct their algorithm (see Table 3$)$. In contrast to Study 1, algorithms were most often based on statistical analyses of data from one's organization, or other relevant data (54\%). Furthermore, unit weighting was common (44\%), and relatively more common than in Study 1. Other ways of determining algorithms were similarly often reported as in Study 1.

\section{Algorithm Appreciation}

We also asked participants who indicated using algorithms at least to some extent $(n=$ 219) why (see Table 7). Commonly reported reasons were that algorithms are more valid (45\%), easier to use (37\%), yield more valuable information (34\%), and are fairer (32\%) than holistic prediction. Relatively uncommon reasons were that algorithms are legally safer $(22 \%)$ and reinforce the employer brand more effectively (18\%) than holistic prediction. Only four participants thought algorithms would be cheaper than holistic prediction (2\%).

\footnotetext{
${ }^{4}$ As a robustness check, we inspected the results when only considering participants who answered at least two items correctly (see Supplement S5). The results were closely in line with the results of the full sample.
} 


\section{Table 7}

Reasons to Use an Algorithm - Results from Study 2

Reasons to Use an Algorithm

Higher predictive validity compared to combining information through my own judgment

Easier to use than combining information through my own judgment

Yields more valuable information than combining information through my own judgment

Fairer than combining information through my own judgment

Prior positive experience with using a rule

Reduces time to hire more effectively than combining information through my own judgment

Reduces time required of the professional compared to combining information through my own judgment

It feels legally safer than combining information through my own judgment

More transparent than combining information through my own judgment

Reinforces employer brand more effectively than combining information through my own judgment

Cheaper than combining information through my own judgment
Proportion and $95 \% \mathrm{CI}$

$.45[.38, .51]$

$.37[.31, .44]$

$.34[.28, .40]$

$.32[.26, .38]$

$.26[.21, .32]$

$.26[.20, .31]$

$.24[.19, .30]$

$.22[.17, .28]$

$.22[.17, .28]$

$.18[.13, .23]$

$.02[.00, .04]$

Note. $N=219$. Multiple answers possible. 


\section{Discussion Study 1 and Study 2}

The results from Study 1 and 2 showed that most selection decisions are made holistically and usually in teams. Frequently mentioned reasons why algorithms are not (always) used were that stakeholders do not accept the use of algorithms and that decision makers believe a combination of holistic and mechanical prediction results in the best decisions. Other reasons in Study 1 were that decision makers cannot or do not want to quantify information, and that algorithms are unavailable. Other reasons in Study 2 were that decision makers considered it their professional duty to use holistic prediction and felt a loss of autonomy and status when they would use algorithms. Decision makers who use some form of mechanical prediction mainly do so because of its validity advantages over holistic prediction, and they often base their algorithms on scientific research findings, a discussion with experts (Study 1), and unit weights (Study 2). Despite presenting participants with an elaborate explanation on holistic and mechanical prediction, only a (small) minority answered all knowledge items correctly, suggesting that many misunderstandings regarding evidencebased decision making still exist. Lastly, we found consistent evidence that reading the academic literature and possessing an assessment license were positively related to the use of mechanical methods. Yet, unexpectedly, we also found that these factors correlated positively with the use of holistic methods in Study 2. This finding is not in line with the results from Study 1, where the use of holistic methods correlated negatively with reading the academic literature and possessing an assessment license, as one would expect. We do not have a plausible explanation for this latter, inconsistent finding.

\section{Study 3}

The aim of Study 3 was to supplement the quantitative surveys with qualitative data from focus groups and to investigate what is needed to increase algorithm use in practice.

\section{Method}




\section{Participants and Procedure}

Participants were members of the Dutch Association of Psychology (Dutch:

Nederlands Instituut voor Psychologen, NIP) who indicated their willingness to participate in future research on test use and decision making in an earlier survey on psychological testing, conducted in collaboration with the European Federation of Psychologists' Associations. We invited these members via email to take part in one of three online focus group sessions on decision making in practice. Due to a technical error, the third focus group session was not recorded. Therefore, we only report the results of the first two sessions. Decision makers (mostly psychologists) with backgrounds in I-O, clinical, developmental, forensic, and educational psychology participated in the focus groups. There were nine and 12 participants in focus group 1 and 2, respectively. Participants read an elaborate explanation on the distinction between holistic and mechanical prediction before signing up for a focus group session. They received a presentation on the distinction again at the beginning of the session and consequently responded to two questions: (1) "What is the reason you think decision makers do not (or seldom) apply mechanical methods in decision making?" and (2) "What is needed to apply mechanical methods more often?"

We applied thematic analysis to analyze our data (Braun \& Clarke, 2006). The third author transcribed the audio material of the two focus group sessions. Then, the authors worked in two pairs. Each pair read the text from both focus groups and classified the text into units. Differences in unit classification were resolved by discussion among the authors. Seven themes were suggested based on inspection of the different units (see Table 8). Second, two newly formed author pairs assigned the units to the themes. Each pair coded one focus group. The pairs could choose a second theme when in doubt which theme to choose. Across focus groups, there was moderate agreement between the two raters $(\kappa=.53)$. Differences in assigned units were resolved by discussion within author pairs. Eventually, each pair received 
all codes and independently wrote a results section. The first author integrated the results sections as presented in the paper. Per theme, we present exemplary quotes in Supplement S6, Table S1.

\section{Table 8}

Frequencies of the Units across Focus Groups per Theme

\begin{tabular}{lcc}
\hline \multicolumn{1}{c}{ Theme } & Choice 1 & Choice 2 \\
\hline $\begin{array}{l}\text { 1. Advantages of mechanical methods } \\
\text { 2. Disadvantages of mechanical methods }\end{array}$ & 23 & 0 \\
3. Advantages of holistic methods & 0 & 1 \\
4. Disadvantages of holistic methods & 4 & 0 \\
5. What is needed to increase the use of mechanical methods? & & \\
$\quad$ 5.1. Providing information and guidelines & 29 & 2 \\
$\quad$ 5.2. Where should information about mechanical methods be & 19 & 0 \\
exchanged? & & 2 \\
$\quad$ 5.3 Who should be responsible for encouraging the use of & 11 & \\
mechanical methods? & & 71 \\
6. Questions about how to use mechanical methods & 29 & 22 \\
7. Reasons why decision makers do not use mechanical methods \\
$\begin{array}{l}\text { 8. Did not fall under a theme } \\
\text { Total }\end{array}$
\end{tabular}

Note. Choice 1 = raters' first choice. Choice 2 = raters' second choice.

\section{Results}

Table 8 shows that most units were assigned to primary theme 6 (questions about how to use mechanical methods), 2 (disadvantages of mechanical methods), 7 (reasons why decision makers do not use mechanical methods), and 5.1 (what is needed to increase the use of mechanical methods: information and guidelines). When also considering secondary themes, most units were assigned to theme 7 . 
A summary of our research findings per theme can be found in Table 9. Within themes, we reported participants' remarks based on how frequently they were mentioned, in descending order. Many participants mentioned that transparency would be a great advantage of mechanical methods. Yet, they also mentioned that the use of algorithms could be inefficient because the criteria of interest may change, specific positions may require specific algorithms, and literature searches to determine predictor weights may be time-consuming. Interestingly, although our participants reported that they usually apply holistic methods, almost no participant mentioned advantages of the holistic method. One participant said that you could also make holistic predictions fully transparent by exactly describing what you do. Some participants were aware of the evidence that mechanical methods are more valid than holistic methods. To increase the use of mechanical methods, participants desired a discussion of this topic in test guidelines, and they suggested that more education is needed. Furthermore, they mentioned that training on how to apply algorithms would be valuable, as well as a database that contains evidence-based algorithms. Lastly, comparing holistic and mechanical prediction within companies would help to recognize differences in predictive validity. In general, participants mentioned that they would like test commissions and universities to spend more attention to this topic.

Our focus groups revealed that many questions and misunderstandings regarding mechanical methods existed, which partly explained why they are seldom used. Participants thought mechanical prediction would only be possible with well-measured variables and evidence-based weights. Furthermore, they considered many decisions too complex to use an algorithm for, and they highlighted the importance of considering the context. Some also thought that it would be a psychologist's job to use holistic methods, while others considered psychologists as "stubborn". Lastly, participants mentioned that other stakeholders in the field would not accept the use of mechanical methods. 


\section{Table 9}

Summary of the Qualitative Research Findings per Research Theme

\begin{tabular}{|c|c|}
\hline Research Theme & Summary of the Research Findings (Participants' Remarks) \\
\hline Advantages of mechanical methods (theme 1) & $\begin{array}{l}\text { - Using an explicit algorithm would make decisions transparent and would provide } \\
\text { insight into how decisions are made (i.e., how information is weighted). } \\
\text { - } \quad \text { Mechanical prediction would elicit critical thinking and "creates awareness". } \\
\text { - } \quad \text { Algorithms would serve as an "anchor", heuristic, or decision aid. Decision makers } \\
\text { could learn from it, but also adjust it to their needs, given a justification. }\end{array}$ \\
\hline Disadvantages of mechanical methods (theme 2) & $\begin{array}{l}\text { - The criterion of interest would constantly change. } \\
\text { - It would be inefficient to design an algorithm for a specific function in an organization } \\
\text { because such a selection takes place only one or two times a year, maybe even less } \\
\text { often. } \\
\text { - } \quad \text { It would be difficult and time-consuming to choose predictor weights, and decision } \\
\text { makers would not have the time and motivation to consult the literature for predictor } \\
\text { validities and weights. } \\
\text { - Mechanical methods would disregard uncertainty around point estimates. } \\
\text { - Some existing algorithms (e.g., in recidivism risk assessment) include controversial } \\
\text { predictors such as a person's zip code. }\end{array}$ \\
\hline Advantages of holistic methods (theme 3) & $\begin{array}{l}\text { - Holistic predictions could also be made fully transparent by exactly telling what you } \\
\text { do. }\end{array}$ \\
\hline
\end{tabular}


Disadvantages of holistic methods (theme 4)

What is needed to increase the use of mechanical methods? Providing information and guidelines (theme 5.1)

Where should information about mechanical methods be exchanged? (theme 5.2)
- Decision makers (including psychologists) would be bad at combining information holistically, as research has shown. They would also put the most weight on things they had seen themselves, and they would think that instruments like cognitive ability tests were less important.

- Mechanical prediction would have to be discussed and explained in guidelines in more detail.

- Training in applying algorithms would be needed.

- Obtaining more information from test commissions on test reliability and validity would make the choice of predictor weights easier.

- Access to information on algorithms would need to be improved.

- Ideally, a database with possible algorithms per sub-discipline would be available.

- Evaluating the validity of algorithms and comparing it to current holistic predictions would stimulate its use in practice.

- More attention to algorithm use in the regular professional training and education (e.g., in the bachelor, master, and post-master in psychology) would be needed.

- Specific courses devoted to mechanical prediction should be created.

- Decision makers within or across companies or institutes could discusses how they decide in particular cases and based on this information suggest specific algorithms.

- Communities could report which specific algorithms work in their case, and upload those to a system so that others could use them as well. 
Who should be responsible for encouraging the use of mechanical methods? (theme 5.3)

Questions about how to use mechanical methods (theme 6)
- Universities should be in charge to accommodate decision making more in their curriculum.

- Testing commissions and other diagnostics institutes were expected to cover decision making in more detail.

- In the field of personnel selection, consulting firms should collaborate with scientists and collect data on applicants and later performance that may be used to design algorithms.

- For many participants it was unclear what exactly an algorithm was and how to use it, although we had asked participants to read our explanation of holistic and mechanical methods before the session.

- It was unclear whether algorithms would have to be communicated to everyone involved in the decision-making process, or whether you could also construct individual algorithms. A

- It was also unclear that one could choose predictor weights oneself, and that this does not necessarily have to be evidence-based.

- It was asked whether the data combination method would still matter if valid, evidence-based predictors are used.

- Participants were confused that the scoring of a test could also be distinguished with regard to the holistic and mechanical method.

- Participants asked what to discuss in group discussions when one wants to implement the mechanical method. 
Reasons why decision makers do not use mechanical methods (theme 7)
- Holistic and mechanical prediction would not be sufficiently taught at the university.

- The distinction between holistic and mechanical prediction was unclear, and there were many misunderstandings.

- Participants thought mechanical prediction would be only possible when solely wellmeasured variables are available.

- Participants also thought the situations in which they have to make decisions are too complex to apply algorithms.

- It was mentioned that algorithms would ignore the individual, and that information should be differently weighted in different situations.

- It would be the role of the psychologist to identify situations in which information should be weighted differently.

- Psychologists could be "stubborn" and (think) they have a lot of knowledge and can predict events better than an algorithm by using their gut feeling.

- Algorithms are rarely used because they would not be accepted in the field.

- Organizational cultures could foster or impede algorithm use. Organizations with a stronger focus on quantitative than on qualitative information would appreciate algorithms more.

- Information on how to construct algorithms is not easily available.

- It would be too time-consuming to find and read the literature on how to construct algorithms. 
- Algorithms, and in particular the use of cutoff scores, would create an illusion of certainty. Things either do or do not happen. 


\section{General Discussion}

In line with earlier research (Ryan \& Sackett, 1987), we consistently found that most decisions are made holistically in practice, usually in teams. Across three studies, conducted in different settings and countries, we found that decision makers rarely use algorithms because they lack knowledge and fear negative evaluations from stakeholders when using algorithms. Moreover, participants in Study 1 indicated that they cannot or do not want to quantify information. Also, participants mentioned that algorithms (Study 1) and information to construct them (Study 3) are often unavailable. Participants in Study 2 also reported that their autonomy and status is reduced when using algorithms, and that they consider it their duty to use holistic prediction (also mentioned in Study 3). Furthermore, Study 1 and 2 showed that reading the academic literature and being licensed were positively related to algorithm use. Yet, unexpectedly, we also found that these variables were positively related to the use of holistic methods in Study 2. Decision makers who use algorithms do so mainly because of its validity advantages over holistic prediction, and they often construct algorithms based on research findings (e.g., meta-analyses) and expert discussions (Study 1), or organizational data or unit weights (Study 2). Lastly, our results from Study 3 suggest that more training and support in using algorithms is needed to increase its use in practice.

Although we supplemented two quantitative surveys with qualitative research to achieve methodological triangulation (Campbell \& Fiske, 1959), our studies have several limitations. We used a small convenience sample in Study 1. Therefore, the results may not generalize to other decision makers involved in selection decisions. Despite a larger and more diverse sample in Study 2, concerns exist regarding the quality of the data, as less participants answered all knowledge check items correctly compared to Study 1. It could be that participants in Study 1 were more intrinsically motivated to learn about evidence-based decision making and hence read the explanation on mechanical and holistic methods more 
carefully. Yet, in Study 2, the results from a subsample of participants who answered at least two knowledge check items correctly were very similar to the results from the full sample, and most results were in line with the results found in the other studies. Still, given the concerns regarding data quality in Study 2, we primarily interpreted the results from Study 1 and 3. Moreover, we cannot rule out that some participants mistakenly reported using mechanical prediction, given the many misunderstandings we observed. We found similar results regarding algorithm use when making hiring decisions in three Western countries. We have no reason to assume that our results would not generalize to other countries in the Western world, given our robust findings and similar findings in other contexts than personnel selection, such as in clinical practice (Vrieze \& Grove, 2009). However, investigating algorithm use in selection decisions in other countries would be valuable. Lastly, due to our cross-sectional, correlational designs, we cannot infer causality.

\section{Implications and Future Directions}

The field of assessment and selection has experienced an increase in automated and algorithmic solutions, mainly in terms of how and what applicant information is collected (Gonzalez et al., 2019). However, our results suggest that algorithms are still rarely used to make selection decisions. We do not expect that complete reliance on mechanical methods to make selection decisions will drastically increase soon, partly because the most commonly mentioned reasons why algorithms are underutilized were diverse, including a lack of training, but also socio-psychological factors such as restricted autonomy and negative stakeholder perceptions when using algorithms. Therefore, it seems promising to investigate when decision makers are most likely to at least take algorithmic advice into account, as this should also increase judgment consistency and hence predictive validity (Yu \& Kuncel, 2020). 
Our results have several implications for advancing research on algorithm aversion and improving decision making in practice. First, we found that decisions are often made holistically in teams. Yet, existing research on algorithm aversion has mostly focused on individual decision makers (Neumann et al., 2021). Therefore, research on the role of mechanical methods in team decision making would be very valuable. We suggest that researchers adopt the lens model (Brunswik, 1955), which is a useful framework to study both individual and team selection decisions (Kuncel, 2018). This model allows researchers to compare how predictors are related to a criterion (e.g., job performance), and to a decisionmaker's or a team's holistic predictions. Predictors can include applicant information such as test scores and interview ratings, but also predictions of an algorithm or holistic predictions from others, in case of hierarchical groups where one member is responsible for the final selection decision and receives advice from others (Hollenbeck et al., 1995). In many selection procedures, a line manager makes the final hiring decision based on the available information and expert advice. An interesting question to be studied in the future is, for example, whether line managers weight expert advice more strongly when the expert has completed a training on evidence-based decision making.

Procedural aspects could also affect algorithm use (for a review of procedural aspects that affect team effectiveness, see Mathieu et al., 2019). Do teams who receive advice from a self-designed algorithm make more accurate predictions than teams who make pure holistic predictions? Do teams make more valid predictions when their discussion is moderated by an assessment expert? Lastly, decision makers may be more likely to use algorithmic advice when the algorithm 'explains itself' by providing a story, as humans also typically explain and justify their holistic decisions (Bolander \& Sandberg, 2013). Adding such narrative elements may improve both individual and team decision making. 
Second, given that knowledge on evidence-based decision making seems to increase algorithm use and predictive accuracy (Neumann, Hengeveld, et al., 2022), decision making should receive much more attention in licenses and the education of practitioners, for example, in on-going organizational trainings. Also, textbooks on psychological and educational testing and test guidelines such as those of the APA/NCME and of the ITC currently do not discuss the benefits of mechanical methods (Meijer et al., 2022). In our opinion, this should change. However, this may not be enough. In line with the broader literature on the science-practice gap (Rynes et al., 2002), our results showed that decision makers rather consult the professional than the academic literature to obtain information on how to best make hiring decisions. Yet, the professional literature contains much misinformation, and evidence-based decision making is hardly discussed (Neumann et al., 2021). Therefore, information on evidence-based decision making should be disseminated in other outlets next to academic journals, such as trade books, professional journals, social media platforms (e.g., LinkedIn), and popular podcasts. Furthermore, organizations like SIOP and EAWOP could assist in information campaigns to reduce misinformation (Lewandowsky et al., 2012). Additionally, a (virtual) drop-in center may be established where practitioners can ask experts questions regarding the implementation of algorithms. The resulting input from practitioners may also meaningfully inform theory development on algorithm aversion.

Third, many participants noticed that algorithms are unavailable, which suggests that they think algorithms have to be complex, as Grove and Meehl (1996) already noted. Yet, as we discussed, even simple algorithms often outperform holistic prediction (Sackett et al., 2017; Yu \& Kuncel, 2020). To increase the availability of algorithms and relevant information, testing commissions and consultancies may create decision aids that document evidence-based algorithms for different predictor sets, or support decision makers in 
developing their own algorithms, such as the ShinyApps by Failenschmid et al. (2021) and Song et al. (2017).

Fourth, and in line with Nolan et al. (2016), we consistently found that decision makers fear negative evaluations from stakeholders when using algorithms. Therefore, research on improving (decision-makers' concerns about) stakeholders' perceptions seems valuable. Furthermore, our results showed that many participants believed a combination of holistic and mechanical methods to result in the best decisions. We found that decision makers mostly combined these two methods in the form of clinical rather than mechanical synthesis. Yet, it remains unknown how clinical and mechanical synthesis compare in terms of usage and predictive validity. Therefore, future research may compare these two methods.

Fifth, our results suggest that decision makers may be more likely to use simple algorithms due to increased transparency and potentially higher fairness (perceptions), rather than due to higher predictive validity. We speculate that people intuitively devise a narrative that "a fair treatment requires equal weights (across applicants)". So, it may be easier for people to see the need for judgment consistency when fairness rather than predictive validity is emphasized. In sum, emphasizing other valuable outcomes such as fairness may help in encouraging (simple) algorithm use.

\section{Conclusion}

Although mechanical methods are superior to holistic methods, they are still rarely used, suggesting that there is much room for improving decision making in practice. Many reasons for this underutilization relate to a lack of knowledge of evidence-based decision making. Therefore, proper and elaborate education and providing support in evidence-based decision making seems to be the first step. 


\section{References}

Arkes, H. R. (2008). Being an advocate for linear models of judgment is not an easy life. In J. I. Krueger (Ed.), Rationality and social responsibility: Essays in honor of Robyn Mason Dawes. (pp. 47-70). Psychology Press.

Arkes, H. R., Dawes, R. M., \& Christensen, C. (1986). Factors influencing the use of a decision rule in a probabilistic task. Organizational Behavior and Human Decision Processes, 37(1), 93-110. https://doi.org/10.1016/0749-5978(86)90046-4

Armstrong, J. S. (2001). Judgmental bootstrapping: Inferring experts' rules for forecasting. In J. S. Armstrong (Ed.), Principles of forecasting: A handbook for researchers and practitioners (pp. 171-192). Springer. https://doi.org/10.1007/978-0-306-47630-3_9

Berkman, E. T., \& Wilson, S. M. (2021). So useful as a good theory? The practicality crisis in (social) psychological theory. Perspectives on Psychological Science, 16(4), 864-874. https://doi.org/10.1177/1745691620969650

Bobko, P., Roth, P. L., \& Buster, M. A. (2007). The usefulness of unit weights in creating composite scores: A literature review, application to content validity, and metaanalysis. Organizational Research Methods, 10(4), 689-709. https://doi.org/10.1177/1094428106294734

Bolander, P., \& Sandberg, J. (2013). How employee selection decisions are made in practice. Organization Studies, 34(3), 285-311. https://doi.org/10.1177/0170840612464757

Braun, V., \& Clarke, V. (2006). Using thematic analysis in psychology. Qualitative Research in Psychology, 3(2), 77-101. https://doi.org/10.1191/1478088706qp063oa

Brunswik, E. (1955). Representative design and probabilistic theory in a functional psychology. Psychological Review, 62(3), 193-217. https://doi.org/10.1037/h0047470 
Burton, J. W., Stein, M. K., \& Jensen, T. B. (2020). A systematic review of algorithm aversion in augmented decision making. Journal of Behavioral Decision Making, 33(2), 220-239. https://doi.org/10.1002/bdm.2155

Campbell, D. T., \& Fiske, D. W. (1959). Convergent and discriminant validation by the multitrait-multimethod matrix. Psychological Bulletin, 56(2), 81-105. https://doi.org/10.1037/h0046016

Dawes, R. M. (1979). The robust beauty of improper linear models in decision making. American Psychologist, 34(7), 571-582. https://doi.org/10.1037/0003-066X.34.7.571

Dawes, R. M., Faust, D., \& Meehl, P. E. (1989). Clinical versus actuarial judgment. Science, 243(4899), 1668-1674. https://doi.org/10.1126/science.2648573

Diab, D. L., Pui, S., Yankelevich, M., \& Highhouse, S. (2011). Lay perceptions of selection decision aids in US and non-US samples. International Journal of Selection and Assessment, 19(2), 209-216. https://doi.org/10.1111/j.1468-2389.2011.00548.x

Dietvorst, B. J., Simmons, J. P., \& Massey, C. (2015). Algorithm aversion: People erroneously avoid algorithms after seeing them err. Journal of Experimental Psychology: General, 144(1), 114-126. https://doi.org/10.1037/xge0000033

Dietvorst, B. J., Simmons, J. P., \& Massey, C. (2018). Overcoming algorithm aversion: People will use imperfect algorithms if they can (even slightly) modify them. Management Science, 64(3), 1155-1170. https://doi.org/10.1287/mnsc.2016.2643

Eronen, M. I., \& Bringmann, L. F. (2021). The theory crisis in psychology: How to move forward. Perspectives on Psychological Science, 16(4), 779-788. https://doi.org/10.1177/1745691620970586

Failenschmid, J. I., Neumann, M., Meijer, R. R., \& Niessen, A. S. M. (2021). The predictive validity of weighted combinations of predictors and criteria [Shiny App]. 
Fokkema, M., Smits, N., Kelderman, H., \& Penninx, B. W. J. H. (2015). Connecting clinical and actuarial prediction with rule-based methods. Psychological Assessment, 27(2), 636-644. https://doi.org/10.1037/PAS0000072

Furnham, A. (2008). HR professionals' beliefs about, and knowledge of, assessment techniques and psychometric tests. International Journal of Selection and Assessment, 16(3), 300-305. https://doi.org/10.1111/j.1468-2389.2008.00436.x

Goldberg, L. R. (1970). Man versus model of man: A rationale, plus some evidence, for a method of improving on clinical inferences. Psychological Bulletin, 73(6), 422-432. https://doi.org/10.1037/h0029230

Gonzalez, M., Capman, J., Oswald, F., Theys, E., \& Tomczak, D. (2019). “Where's the I-O?” Artificial intelligence and machine learning in talent management systems. Personnel Assessment and Decisions, 5(3), 33-44. https://doi.org/10.25035/pad.2019.03.005

Grömping, U. (2006). Relative importance for linear regression in R: The package relaimpo. Journal of Statistical Software, 17, 1-27. https://doi.org/10.18637/jss.v017.i01

Grove, W. M., \& Meehl, P. E. (1996). Comparative efficiency of informal (subjective, impressionistic) and formal (mechanical, algorithmic) prediction procedures: The Clinical-Statistical Controversy. Psychology, Public Policy, and Law, 2(2), 293-323. https://doi.org/10.1037/1076-8971.2.2.293

Grove, W. M., Zald, D. H., Lebow, B. S., Snitz, B. E., \& Nelson, C. (2000). Clinical versus mechanical prediction: A meta-analysis. Psychological Assessment, 12(1), 19-30. https://doi.org/10.1037/1040-3590.12.1.19

Highhouse, S. (2008). Stubborn reliance on intuition and subjectivity in employee selection. Industrial and Organizational Psychology: Perspectives on Science and Practice, 1(3), 333-342. https://doi.org/10.1111/j.1754-9434.2008.00058.x 
Hollenbeck, J. R., Ilgen, D. R., Sego, D. J., Hedlund, J., Major, D. A., \& Phillips, J. (1995). Multilevel theory of team decision making: Decision performance in teams incorporating distributed expertise. Journal of Applied Psychology, 80(2), 292-316. https://doi.org/10.1037/0021-9010.80.2.292

Jackson, D. J. R., Dewberry, C., Gallagher, J., \& Close, L. (2018). A comparative study of practitioner perceptions of selection methods in the United Kingdom. Journal of Occupational and Organizational Psychology, 91(1), 33-56. https://doi.org/10.1111/joop.12187

König, C. J., Klehe, U., Berchtold, M., \& Kleinmann, M. (2010). Reasons for being selective when choosing personnel selection procedures. International Journal of Selection and Assessment, 18(1), 17-27. http://dx.doi.org/10.1111/j.1468-2389.2010.00485.x

Kuncel, N. R. (2018). Judgment and decision making in staffing research and practice. In D. S. Ones, N. Anderson, C. Viswesvaran, \& H. K. Sinangil (Eds.), The sage handbook of industrial, work and organizational psychology (2nd ed., pp. 474-487). SAGE Publications Ltd. https://doi.org/10.4135/9781473914940

Kuncel, N. R., Klieger, D. M., Connelly, B. S., \& Ones, D. S. (2013). Mechanical versus clinical data combination in selection and admissions decisions: A meta-analysis. Journal of Applied Psychology, 98(6), 1060-1072. https://doi.org/10.1037/a0034156

Landers, R. N., \& Behrend, T. S. (2022). Auditing the AI auditors: A framework for evaluating fairness and bias in high stakes AI predictive models. American Psychologist. https://doi.org/10.1037/AMP0000972

Landers, R. N., \& Sanchez, D. R. (2022). Game-based, gamified, and gamefully designed assessments for employee selection: Definitions, distinctions, design, and validation. International Journal of Selection and Assessment, 30(1), 1-13. https://doi.org/10.1111/IJSA.12376 
Lewandowsky, S., Ecker, U. K. H., Seifert, C. M., Schwarz, N., \& Cook, J. (2012).

Misinformation and its correction: Continued influence and successful debiasing. Psychological Science in the Public Interest, 13(3), 106-131.

Lodato, M. A., Highhouse, S., \& Brooks, M. E. (2011). Predicting professional preferences for intuition-based hiring. Journal of Managerial Psychology, 26(5), 352-365. https://doi.org/10.1108/02683941111138985

Logg, J. M., Minson, J. A., \& Moore, D. A. (2019). Algorithm appreciation: People prefer algorithmic to human judgment. Organizational Behavior and Human Decision Processes, 151, 90-103. https://doi.org/10.1016/j.obhdp.2018.12.005

Mann, S. L., \& Chowhan, J. (2011). Selection practices in canadian firms: An empirical investigation. International Journal of Selection and Assessment, 19(4), 435-437. https://doi.org/10.1111/j.1468-2389.2011.00571.x

Mathieu, J. E., Gallagher, P. T., Domingo, M. A., \& Klock, E. A. (2019). Embracing complexity: Reviewing the past decade of team effectiveness research. Annual Review of Organizational Psychology and Organizational Behavior, 6(1), 17-46. https://doi.org/10.1146/annurev-orgpsych-012218-015106

Meehl, P. E. (1954). Empirical comparisons of clinical and actuarial prediction. In P. E. Meehl (Ed.), Clinical versus statistical prediction: A theoretical analysis and a review of the evidence (pp. 83-128). University of Minnesota Press. https://doi.org/doi:10.1037/11281-008

Meijer, R. R., Neumann, M., Hemker, B. T., \& Niessen, A. S. M. (2020). A tutorial on mechanical decision-making for personnel and educational selection. Frontiers in Psychology, 10, Article 3002. https://doi.org/10.3389/fpsyg.2019.03002 
Meijer, R. R., \& Niessen, A. S. M. (2022). Personnel selection as judgment and decision science: An introduction. International Journal of Selection and Assessment. https://doi.org/10.1111/IJSA.12377

Meijer, R. R., Niessen, A. S. M., \& Neumann, M. (2022). Psychological and educational testing and decision making: The lack of knowledge dissemination in textbooks and test guidelines. In L. A. van de Ark, W. H. M. Emons, \& R. R. Meijer (Eds.), Practical measurement: Essays on contemporary psychometrics. https://doi.org/10.1007/978-3-031-10370-4_3

Morris, S. B., Daisley, R. L., Wheeler, M., \& Boyer, P. (2015). A meta-analysis of the relationship between individual assessments and job performance. Journal of Applied Psychology, 100(1), 5-20. https://doi.org/10.1037/a0036938

Neumann, M., Hengeveld, M., Niessen, A. S. M., Tendeiro, J. N., \& Meijer, R. R. (2022). Education increases decision-rule use: An investigation of education and incentives to improve decision making. Journal of Experimental Psychology: Applied, 28(1), 166178. https://doi.org/10.1037/xap0000372

Neumann, M., Niessen, A. S. M., \& Meijer, R. R. (2021). Implementing evidence-based assessment and selection in organizations: A review and an agenda for future research. Organizational Psychology Review, 11(3), 205-239. https://doi.org/10.1177/2041386620983419

Neumann, M., Niessen, A. S. M., Tendeiro, J. N., \& Meijer, R. R. (2022). The autonomyvalidity dilemma in mechanical prediction procedures: The quest for a compromise. Journal of Behavioral Decision Making, 35(4), e2270. https://doi.org/10.1002/bdm.2270

Nolan, K. P., Carter, N. T., \& Dalal, D. K. (2016). Threat of technological unemployment: Are hiring managers discounted for using standardized employee selection practices? 
Personnel Assessment and Decisions, 2(1), 30-47.

https://doi.org/10.25035/pad.2016.004

Nolan, K. P., \& Highhouse, S. (2014). Need for autonomy and resistance to standardized employee selection practices. Human Performance, 27(4), 328-346. https://doi.org/10.1080/08959285.2014.929691

Piotrowski, C., \& Armstrong, T. (2006). Current recruitment and selection practices: A national survey of fortune 1000 firms. North American Journal of Psychology, 8(3), 489-496.

Ployhart, R. E., \& Bartunek, J. M. (2019). Editors' comments: There is nothing so theoretical as good practice - A call for phenomenal theory. Academy of Management Review, 44, 493-497. https://doi.org/10.5465/amr.2019.0087

Risavy, S. D., Fisher, P. A., Robie, C. R., \& König, C. J. (2019). Selection tool use: A focus on personality testing in Canada, the United States, and Germany. Personnel Assessment and Decisions, 5(1), 62-72. https://doi.org/10.25035/pad.2019.01.004

Ryan, A. M., Inceoglu, I., Bartram, D., Golubovich, J., Grand, J., Reeder, M., Derous, E., Nikolaou, I., \& Yao, X. (2015). Trends in testing: Highlights of a global survey. In I. Nikolaou \& J. Oostrom (Eds.), Employee recruitment, selection, and assessment: Contemporary issues for theory and practice (pp. 136-153).

Ryan, A. M., \& Sackett, P. R. (1987). A survey of individual assessment practices by I/O psychologists. Personnel Psychology, 40(3), 455-488. http://dx.doi.org/10.1111/j.1744-6570.1987.tb00610.x

Rynes, S. L., Colbert, A. E., \& Brown, K. G. (2002). HR professionals' beliefs about effective human resource practices: Correspondence between research and practice. Human Resource Management, 41(2), 149-174. https://doi.org/10.1002/hrm.10029 
Sackett, P. R., Dahlke, J. A., Shewach, O. R., \& Kuncel, N. R. (2017). Effects of predictor weighting methods on incremental validity. Journal of Applied Psychology, 102(10), 1421-1434. https://doi.org/10.1037/ap10000235

Sawyer, J. (1966). Measurement and prediction, clinical and statistical. Psychological Bulletin, 66(3), 178-200. https://doi.org/10.1037/h0023624

Song, Q. C., Wee, S., \& Newman, D. A. (2017). Diversity shrinkage: Cross-validating Paretooptimal weights to enhance diversity via hiring practices. Journal of Applied Psychology, 102(12), 1636-1657. https://doi.org/10.1037/ap10000240

Vrieze, S. I., \& Grove, W. M. (2009). Survey on the use of clinical and mechanical prediction methods in clinical psychology. Professional Psychology: Research and Practice, 40(5), 525-531. https://doi.org/10.1037/a0014693

Yu, M. C., \& Kuncel, N. R. (2020). Pushing the limits for judgmental consistency: Comparing random weighting schemes with expert judgments. Personnel Assessment and Decisions, 6(2), 1-10. https://scholarworks.bgsu.edu/pad/vol6/iss2/2

Zibarras, L. D., \& Woods, S. A. (2010). A survey of UK selection practices across different organization sizes and industry sectors. Journal of Occupational and Organizational Psychology, 83(2), 499-511. https://doi.org/10.1348/096317909X425203 